Ann. rheum. Dis. (1979), 38, Supplement p. 8

\title{
Reiter's syndrome: evaluation of proposed criteria
}

\author{
ROBERT F. WILLKENS, FRANK C. ARNETT, THOMAS BITTER, \\ ANDREI CALIN, LLOYD FISHER, DENYS K. FORD, ARMIN E. GOOD, \\ AND ALFONSE T. MASI ${ }^{1}$
}

From the University of Washington, Seattle, USA; Johns Hopkins University, Baltimore, USA; University of Lausanne, Switzerland; Stanford University, USA; University of British Colombia, Vancouver, Canada; University of Michigan, Ann Arbor, USA; and University of Tennessee, Memphis, USA

Clinical entities in the seronegative spondyloarthropathies $^{329}$ are difficult to delineate and overlap considerably. Classifying Reiter's syndrome (RS) in particular is handicapped by the sporadic occurrence of the endemic disease, the transient nature of the disease in many cases, and the need for relatively long follow-up to establish the presence of $x$-ray changes. The presence of HLA-B27 has not contributed to resolving the problem for RS any more than it has for ankylosing spondylitis. ${ }^{37}$ Thus, in a first attempt, the American Rheumatism Association (ARA) Diagnostic and Therapeutic Criteria Committee has evaluated typical cases from seven university-based arthritis centres retrospectively in an attempt to develop diagnostic criteria for RS.

\section{Design and definitions}

According to the present design participating centres were asked for detailed evaluations of patients with Reiter's syndrome (RS), ankylosing spondylitis (AS), seronegative rheumatoid arthritis (RA), psoriatic arthritis (PsA), and gonococcal arthritis (GcA). The cases of RS to be selected were to be those that were most typical in the investigator's experience. The clinical characteristics (variables) were analysed as in previous ARA diagnostic criteria investigations $\mathrm{s}^{63},{ }^{213}$ as to their relative 'weight' as potential diagnostic criteria.

Since urethritis and mucocutaneous lesions are important diagnostic findings it was necessary to define them. Urethritis is considered evidence of genitourinary inflammation in males* if occurring within one month of the appearance of arthritis. Early morning mucopurulent or seropurulent discharge, however slight, is considered evidence when accompanied by dysuria. If gonococci are

\footnotetext{
${ }^{1}$ Members of the American Rheumatism Association Diagnostic and Therapeutic Criteria Committee.

*Urethritis in women cannot be used as indicative of genital inflammation-Editor.
}

present urethritis-or arthritis-is considered suggestive of RS only if it persists after the administration of a dose of penicillin considered sufficient to eradicate the gonococci.

The mucocutaneous lesions may consist of keratodermia blennorrhagica, balanitis circinata, or typically painless erosions (ulceration) of the oral mucosa. Keratodermia blenorrhagica usually begins on the palms and soles as pustules. Gradually, they become covered with thick, horny crusts. Neighbouring lesions may become confluent. Similar lesions can develop on all cutaneous areas but may be indistinguishable from pustular psoriasis both clinically and histologically.

\section{Results}

A total of 249 case reports submitted from seven centres were analysed for 66 variables. A selection of these data are shown to Table 1 . Historical data, pelvic $x$-ray investigation, and histocompatability typing were not complete in all cases.

Except for one patient with RS all patients analysed had arthritis as a component of their initial attack. Polyarticular presentation greatly exceeded monoarticlular onset. Articular tenderness and/or swelling was assessed with respect to regions of the body affected and to symmetry (Table 2 ). The knees or ankles were affected in $61 \%$ of the RS cases in their initial attack, and heels were swollen and tender in $26 \%$. Heel involvement was asymmetric in twothirds of the 19 cases in which it occurred, but against a background of often asymmetric diseases chosen as controls asymmetry of joint involvement was not a distinguishing characteristic of RS. Diffuse swelling of the toe, the classic 'sausage digit', occurred in $17 \%$ of RS patients but was much more frequent in patients with PsA (52\%). The disease was acute in onset in three-quarters of patients with RS, in all of the cases with GcA, and in $32 \%$ of patients with seronegative RA. 
Table 1 Percentage of RS cases and control patients with specified items during initial attack

\begin{tabular}{|c|c|c|c|c|c|}
\hline & $\begin{array}{l}R S \\
(n=83)\end{array}$ & $\begin{array}{l}A S \\
(n=53)\end{array}$ & $\begin{array}{l}S N R A \\
(n=33)\end{array}$ & $\begin{array}{l}P S A \\
(n=53)\end{array}$ & $\begin{array}{l}G c A \\
(n=27)\end{array}$ \\
\hline Arthritis (peripheral) & 99 & 37 & 100 & 100 & 100 \\
\hline (a) Tendinitis & 25 & 12 & 7 & 6 & 23 \\
\hline (b) Heel pain & 40 & 12 & 0 & 4 & 8 \\
\hline (c) Back pain & 49 & 87 & 0 & 28 & 4 \\
\hline (d) Polyarticular & 81 & 29 & 68 & 84 & 54 \\
\hline (e) Monarticular & 14 & 8 & 30 & 15 & 30 \\
\hline (f) Sausage digits & 17 & 6 & 0 & 52 & 0 \\
\hline \multicolumn{6}{|l|}{ Urethritis (men and } \\
\hline women) & 86 & 4 & 0 & $\mathbf{0}$ & 38 \\
\hline $\begin{array}{l}\text { Cervicitis } \\
\text { (No. of women) }\end{array}$ & $\begin{array}{l}71 \\
(7)\end{array}$ & $\begin{array}{r}0 \\
(6)\end{array}$ & $\begin{array}{c}0 \\
(18)\end{array}$ & $\begin{array}{c}0 \\
(13)\end{array}$ & $\begin{array}{l}33 \\
(18)\end{array}$ \\
\hline Conjunctivitis & 57 & 20 & 0 & 4 & 0 \\
\hline (a) Bilateral & 44 & 8 & - & 4 & - \\
\hline \multicolumn{6}{|l|}{ Mucous membrane } \\
\hline lesions & 31 & 0 & 0 & 2 & 12 \\
\hline \multicolumn{6}{|l|}{ (a) Multiple } \\
\hline locations & 21 & 2 & - & 90 & 54 \\
\hline (b) Nail changes & 9 & 0 & - & 67 & 0 \\
\hline (c) Balanitis & 39 & 0 & - & 2 & 0 \\
\hline Diarrhoea & 14 & 4 & 0 & 0 & 4 \\
\hline Involve CNS & 1 & 2 & 0 & 0 & 0 \\
\hline Fever & 37 & 2 & 6 & 4 & 50 \\
\hline Weight loss & 38 & 4 & 9 & 12 & 0 \\
\hline Acute attack & 78 & 25 & 32 & 19 & 100 \\
\hline \multicolumn{6}{|l|}{$\begin{array}{l}\text { Duration of initial } \\
\text { attack }\end{array}$} \\
\hline $\begin{array}{l}\text { less } \\
\text { (b) One week to }\end{array}$ & $\mathbf{0}$ & 2 & 4 & 2 & 42 \\
\hline one month & 1 & 7 & 4 & 0 & 46 \\
\hline one month & 99 & 91 & 92 & 98 & 12 \\
\hline Positive family history & 13 & 33 & 29 & 30 & 0 \\
\hline $\begin{array}{l}\text { HLA-B27 positive } \\
\text { (No. typed) }\end{array}$ & $\begin{array}{l}86 \\
(77)\end{array}$ & $\begin{array}{l}97 \\
(37)\end{array}$ & $\begin{array}{l}33 \\
(6)\end{array}$ & $\begin{array}{l}47 \\
(19)\end{array}$ & $\begin{array}{r}0 \\
(1)\end{array}$ \\
\hline \multicolumn{6}{|l|}{$\begin{array}{l}X \text {-ray abnormalities } \\
\text { (a) In peripheral }\end{array}$} \\
\hline $\begin{array}{l}\text { joints } \\
\text { (No. of cases) }\end{array}$ & $\begin{array}{l}11 \\
(45)\end{array}$ & $\begin{array}{l}23 \\
(22)\end{array}$ & $\begin{array}{l}64 \\
(14)\end{array}$ & $\begin{array}{l}47 \\
(19)\end{array}$ & $\begin{array}{l}46 \\
(11)\end{array}$ \\
\hline $\begin{array}{l}\text { (b) Sacroiliac joints } \\
\text { (No. of cases) }\end{array}$ & $\begin{array}{l}22 \\
(37)\end{array}$ & $\begin{array}{l}80 \\
(15)\end{array}$ & $\begin{array}{l}11 \\
(9)\end{array}$ & $\begin{array}{l}13 \\
(16)\end{array}$ & $\begin{array}{l}0 \\
(4)\end{array}$ \\
\hline
\end{tabular}

RS $=$ Reiter's syndrome. AS=ankylosing spondylitis. SNRA= definite rheumatoid arthritis (seronegative). PsA = psoriatic arthritis. GcA = gonococcal arthritis.

Table 2 Type of joints involved (per cent of total number of patients) during initial episode/per cent of patients with involvement of the given joint during last examination

\begin{tabular}{lccccc}
\hline Joints involved & $\begin{array}{l}R S \\
(n=74 /\end{array}$ & $\begin{array}{l}A S \\
(n=27 / \\
42)\end{array}$ & $\begin{array}{l}S N R A \\
(n=29 /\end{array}$ & $\begin{array}{l}\text { P3) } \\
(n=31 /\end{array}$ & $\begin{array}{l}G c A \\
(n=24)\end{array}$ \\
& $1 / 1$ & $0 / 2$ & $0 / 6$ & $6 / 0$ & $0 /-$ \\
\hline Jaw & $7 / 3$ & $4 / 2$ & $0 / 3$ & $0 / 4$ & $0 /-$ \\
Neck & & & & & \\
Arms, shoulders, & $28 / 12$ & $22 / 29$ & $59 / 79$ & $51 / 61$ & $67 /-$ \\
$\quad$ wrists & $23 / 14$ & $4 / 4$ & $55 / 76$ & $65 / 67$ & $25 /-$ \\
Hands & $14 / 8$ & $37 / 53$ & $0 / 0$ & $7 / 8$ & $0 /-$ \\
Sacroiliac & $7 / 7$ & $26 / 14$ & $7 / 15$ & $3 / 6$ & $0 /-$ \\
Hips & $61 / 28$ & $22 / 14$ & $72 / 63$ & $52 / 45$ & $75 /-$ \\
Knees or ankles & $26 / 13$ & $0 / 8$ & $14 / 30$ & $8 / 10$ & $13 /-$ \\
Heels & $16 / 15$ & $0 / 2$ & $21 / 27$ & $45 / 45$ & $8 /-$ \\
Feet & & & & & \\
\hline
\end{tabular}

Symbols as in footnote to Table 1.
Table 3 'Sensitivity' and 'specificity' of criteria for $R S$

\begin{tabular}{lcc}
\hline 'Sensitivity' & \\
(a) At initial episode & $84 \cdot 3 \%$ & $70 / 83$ \\
(b) Including subsequent attacks & $97 \cdot 6 \%$ & $81 / 83$ \\
'Specificity' against*: & $98 \cdot 2 \%$ & $163 / 166$ \\
(a) All other cases & $96 \cdot 2 \%$ & $51 / 53$ \\
(b) Ankylosing spondylitis & & \\
(c) Definite rheumatoid arthritis & $100 \cdot 0 \%$ & $33 / 33$ \\
(seronegative) & $100 \cdot 0 \%$ & $53 / 53$ \\
(d) Psoriatic arthritis & $96 \cdot 3 \%$ & $26 / 27$ \\
(e) Gonococcal arthritis & & \\
\hline
\end{tabular}

*Initial episode.

Analysis of these (selected) partially retrospective data suggests the following definition of RS:

Clinically acceptable Reiter's syndrome consists of peripheral arthritis occurring in association with urethritis and/or cervicitis. The characteristic episode is of more than one month's duration.

Table 3 summarises the search for the 'sensitivity'* and 'specificity' of these criteria. Remember that 'sensitivity' is the proportion of cases that satisfy criteria (positive findings) among those considered to have the disease to be defined, and 'specificity' the proportion of control patients who do not satisfy particular criteria. Using the above definition 71 of the 83 patients who eventually met the criteria for RS were already 'correctly classified' during the initial episode-that is, with a 'sensitivity' of above criteria of $84.3 \%$ at the end of the first bout. One of the 13 cases incorrectly classified had an initial episode of less than four weeks' duration. The other $12(14.5 \%)$ male patients did not have urethritis during the first episode of arthritis.

Three control patients were misclassified as having RS on the basis of the above criteria. Two of them had been entered as having AS and had, by history, presented the classical triad of RS as well as heel pain. The third patient, with a culture-proved, antibiotic-sensitive GcA, equally satisfied the above criteria as well as displaying heel pain and fever.

The 'specificity' of the above minimal criteria was $98.2 \%$ within the chosen design (Table 3 ).

\section{Discussion}

Eye involvement (conjunctivitis or uveitis, or both), part of Stoll's, ${ }^{298}$ Brodie's, ${ }^{45}$ and Reiter's ${ }^{254}$ triad, as well as a variety of extra-articular manifestations

*Strictly speaking 'sensitivity', 'specificity', and 'correct classification' should be applied only to an unselected continuous series of consecutive cases entered prospectively. Applied to patients selected to be typical, as in the present design and in two previous diagnostic criteria investigations ${ }^{63213}$, they represent a self-confirming circular reasoning, and hence are placed between inverted commas to remind readers of this instrinsic difficulty. 
Table 4 Incidence of 'minor' signs and symptoms of $R S$ during initial attack among correctly and incorrectly classified patients

\begin{tabular}{lll}
\hline Signs and symptoms & $\begin{array}{l}\text { RS cases } \\
\text { correctly } \\
\text { classified } \\
(n=70)\end{array}$ & $\begin{array}{l}\text { RS cases } \\
\text { incorrectly } \\
\text { classified } \\
(n=13)\end{array}$ \\
\hline Bilateral conjunctivitis & $52 \cdot 2$ & $15 \cdot 4(\mathrm{n}=2)$ \\
Unilateral conjunctivitis & $6 \cdot 4$ & 0.0 \\
Balanitis & $45 \cdot 9$ & $7 \cdot 7$ \\
Mucous membrane & $33 \cdot 8$ & 0.0 \\
Heel pain & 43.7 & 25.0 \\
Fever & 40.9 & 10.0 \\
Weight loss & 40.3 & $18 \cdot 2$ \\
\hline
\end{tabular}

(Tables 4,5 ) are known to be part of RS and usually occur synchronously with the appearance of urethritis and/or cervicitis. Thus before formulating any criteria an extensive search (both by human ingenuity and discriminant computer analysis) was undertaken to decide whether eye involvement would afford a positive contribution in delineating the disease pattern of RS.

It was further analysed (Table 4), firstly, whether a set of six 'minor criteria' would improve the definition and discrimination of RS among other patients with seronegative spondarthritides and, secondly, whether such criteria would contribute to the inclusion of 13 patients who had failed initially to meet the above definition. Indeed, five of these 13 initially difficult patients had minor manifestations of RS and all but one was HLA-B27 positive. Only the one patient with the transient initial episode consisting of the full triad (urethritis, arthritis, and conjunctivitis) was B27-negative. This illustrates how B27 positivity sways the diagnosis in favour of RS when criteria are incompletely fulfilled. On mathematical analysis, however, the definition (discrimination) of RS could not be improved by including eye involvement, B27 positivity, or any of the six minor characteristics studied.

Table 5 presents the cumulative incidence of minor signs and symptoms of RS as they may appear in this disease as well as in the other seronegative disease entities analysed in the present study. The RS cases that satisfied the above criteria had an average of 2.4 minor manifestations as against those (an average of 0.7 ) not meeting the proposed criteria. Thus, 10 patients with AS manifested only one of these six features. In other words, $40 \%$ of patients with RS presented at least three minor features, a score reached only by $1.8 \%$ of patients with the other diseases. Minor manifestations definitely predominate in RS. Although in the present highly selected set-up they are not required for better classification of the syndrome they merit clinical attention in long-term studies of patients with RS. ${ }^{181}$

A preliminary attempt was made to search for variables potentially predictive of disease severity. Table 6 shows the relationship between sacroiliac involvement and the duration (presumed severity) of disease. Patients with sacroiliac changes were observed longer than those without, but the difference was not statistically significant.

The presence or absence of HLA-B27 (Table 7) was also examined in relation to sacroiliac involvement in the initial episode and to the presence or absence of selected manifestations. There was little difference, although HLA-B27 positivity was associated more often with skin lesions $(P=0.04)$ and possibly with more frequent weight loss $(P=0.09)$. With the small number of HLA-B27-negative

Table 6 Relationship of radiological sacroiliitis to duration of follow-up

\begin{tabular}{|c|c|c|c|c|}
\hline \multirow[t]{2}{*}{ Sacroiliitis } & \multicolumn{2}{|l|}{ Reiter's disease } & \multicolumn{2}{|c|}{ Ankylosing spondylitis } \\
\hline & $\begin{array}{l}\text { Mean }(S E M) \\
\text { follow-up } \\
\text { (years) }\end{array}$ & $\begin{array}{l}\text { No. of } \\
\text { patients }\end{array}$ & $\begin{array}{l}\text { Mean (SEM) } \\
\text { follow-up } \\
\text { (years) }\end{array}$ & $\begin{array}{l}\text { No. of } \\
\text { patients }\end{array}$ \\
\hline $\begin{array}{l}\text { None } \\
\text { Unilateral } \\
\text { Bilateral }\end{array}$ & $\begin{array}{l}10 \cdot 2( \pm 1 \cdot 5) \\
12 \cdot 8( \pm 4 \cdot 5) \\
11 \cdot 9( \pm 2 \cdot 3)\end{array}$ & $\begin{array}{r}38 \\
6 \\
12\end{array}$ & $\begin{array}{r}13 \cdot 6( \pm 2 \cdot 6) \\
9 \cdot 7( \pm 1 \cdot 4) \\
19 \cdot 1( \pm 1 \cdot 9)\end{array}$ & $\begin{array}{r}5 \\
3 \\
38\end{array}$ \\
\hline
\end{tabular}

Table 5 Cumulative number of 'minor' signs and symptoms* in RS and in seronegative disease entities analysed as controls

\begin{tabular}{|c|c|c|c|c|c|c|}
\hline \multirow[t]{2}{*}{ No. present } & \multicolumn{2}{|l|}{ Reiter's syndrome } & \multirow{2}{*}{$\begin{array}{l}\text { Ankylosing } \\
\text { spondylitis }\end{array}$} & \multirow{2}{*}{$\begin{array}{l}\text { Seronegative } \\
\text { rheumatoid } \\
\text { arthritis }\end{array}$} & \multirow{2}{*}{$\begin{array}{l}\text { Psoriatic } \\
\text { arthritis }\end{array}$} & \multirow{2}{*}{$\begin{array}{l}\text { Gonococcal } \\
\text { arthritis }\end{array}$} \\
\hline & Criteria positive & Criteria negative & & & & \\
\hline $\begin{array}{l}6 \\
5 \\
4 \\
3 \\
2 \\
1 \\
0\end{array}$ & $\begin{array}{r}5 \\
4 \\
10 \\
11 \\
10 \\
14 \\
9\end{array}$ & $\begin{array}{l}0 \\
0 \\
0 \\
1 \\
1 \\
4 \\
7\end{array}$ & $\begin{array}{r}0 \\
0 \\
0 \\
1 \\
0 \\
10 \\
42\end{array}$ & $\begin{array}{r}0 \\
0 \\
0 \\
0 \\
2 \\
1 \\
30\end{array}$ & $\begin{array}{r}0 \\
1 \\
0 \\
0 \\
3 \\
5 \\
46\end{array}$ & $\begin{array}{r}0 \\
0 \\
0 \\
0 \\
4 \\
7 \\
15\end{array}$ \\
\hline
\end{tabular}

* Bilateral eye involvement, fever, weight loss, heel pain, balanitis, mucous membrane lesions. 
Table 7 Proportion of $R S$ cases selected manifestations according to B27 positivity or negativity

\begin{tabular}{llll}
\hline & \multicolumn{2}{l}{$H L A-B 27$} & \\
\cline { 2 - 3 } Selected manifestations & $\begin{array}{l}\text { Positive } \\
(n=63)\end{array}$ & $\begin{array}{l}\text { Negative } \\
(n=11)\end{array}$ & $P$ value* \\
\hline Urethritis & $51 / 62$ & $10 / 11$ & NS \\
Conjunctivitis & $34 / 63$ & $7 / 11$ & NS \\
Mucous membrane & $14 / 54$ & $3 / 10$ & NS \\
Heel pain & $25 / 59$ & $5 / 11$ & NS \\
Polyarticular arthritis & $54 / 63$ & $7 / 11$ & NS \\
Sacroiliac involvement, & & & \\
$\quad X$-ray (initial episode) & $6 / 29$ & $0 / 4$ & NS $\dagger$ \\
Last exam & $15 / 46$ & $2 / 9$ & NS \\
Skin lesions & $31 / 59$ & $2 / 10$ & $0 \cdot 04 \dagger$ \\
Weight loss & $22 / 55$ & $2 / 9$ & $0 \cdot 09$ \\
Fever & $18 / 55$ & $4 / 9$ & NS \\
\hline
\end{tabular}

*Chi-square with continuity correction.

†Two-sided Fisher's exact test.

patients studied, however, it was difficult to demonstrate differences.

\section{Conclusions}

A retrospective evaluation of 83 typical patients with RS and 166 patients with seronegative arthritis selected for comparison has provided a characterisation of what might be accepted as definite RS, using -as had been previously suggested ${ }^{184}$ minimal criteria of arthritis and genital inflammation, provided the episode under scrutiny lasts for at least one month.

Initial attacks may occasionally be incomplete and can be distinguished with increasing confidence depending on the extent of associated 'minor' clinical manifestations beyond arthritis and urethritis or cervicitis.

This report has not thoroughly addressed itself to the issue of cases not fulfilling the primary criteria or of other forms of reactive arthritis mimicking RS, or of patients who develop AS or PsA ${ }^{\mathbf{1 8 1}}$ in the course of RS. The categories of incomplete $R S,{ }^{16}$ reactive arthritis, ${ }^{97}$ AS, PsA, and RA probably represent heterogenous patient groupings and their classification is being vigorously dissected by groups of investigators like Masi ${ }^{211}$ and Schaller. ${ }^{272}$

We thank Drs Currier, McEwen, and Arnold Soren of New York University for the use of their cases, and Jan Lamers and Jane Lucas for their help in data processing.

\section{General discussion}

PROF. V. WRIGHT: Where did your patients come from? An important issue indeed, because what the venereologist sees is very different from what the rheumatologist sees.

PROF. R. F. WILLKENS: Our own patients came from a private rheumatologist's practice and a rheumatology clinic in a teaching hospital in Seattle. PROF. D. K. FORD: In Vancouver they were selected. We selected patients reviewed four years ago on the basis of complete follow-up data.

DR. A. CALIN: At Stanford we have some 100 patients and I randomly selected 10 from this pool. Some were self-referrals and others referred by their physician.

DR. F. C. ARNETT: Ours came from the wards and outpatient clinics of the Johns Hopkins and Good Samaritan Hospitals in Baltimore.

PROF. A. E. GOOD: Eight out of ten of ours came from a Veteran's Administration Hospital and the other two from a university hospital arthritis clinic.

PROF. T. BITTER: As in many other recent publications it is not RS which is difficult to define but rather RA, particularly seronegative, non-erosive disease. So I am not surprised to see in the pre-edited rough of computer data of an RA patient with combined ocular and genital inflammation another one with major sacroiliitis. Would that not rule out the diagnosis of plain RA rheumatoid arthritis, or is this a rare instance of coincident RS and RA?

DR. CALIN: We too had difficulty with the seronegative RA group. This diagnosis was difficult to justify since many patients with this label may have developed a sausage digit at a later stage or some radiological change typical of psoriatic arthropathy. DR. D. A. BREWERTON: Criteria seem to me like a rheumatologist's interpretation of the classical description of RS. What, for instance, are we going to say to the ophthalmologists who see uveitis associated with urethritis in the absence of rheumatoid disease, just as we see people with arthritis? Are we going to say that the uveitis patients don't belong to the club just because Reiter described it so? PROF. WILLKENS: The problem with the development of criteria is that we define a syndrome and then we go to prove what we said in the first place; it is a circular reasoning process.*

PROF. A. S. RUSSELL: Rather like Dr. Brewerton, I am basically opposed to criteria. While criteria are essential if one is describing the natural history and prognosis of a disease, treated or untreated, what bothers me is when students or residents say: 'This patient cannot have Reiter's (or, classically, cannot have rheumatic fever) because he does not fit the criteria.' I think for an individual case criteria are almost irrelevant.

*This has so far been the approach for all ARA elaborated criteria. An alternative, non-circular approach is illustrated in Dr. Arnett's paper, 'Incomplete' RS : clinical comparisons with the classical triad', at page 73-Editor. 